\title{
An experimental test of the ability of Daphnia galeata resting egg production in Lake Biwa
}

\author{
Narumi K. TSUGEKI, ${ }^{1 *}$ Jotaro URABE ${ }^{2}$ \\ ${ }^{1}$ Center for Marine Environmental Studies, Ehime University, 2-5 Bunkyo-cho, Matsuyama 790-8577, Japan; ${ }^{2}$ Graduate School of Life \\ Science, Tohoku University, Katahira 2-1-1, Aoba-ku, Sendai 980-8578, Japan \\ *Corresponding author: tsugeki-kuwae@sci.ehime-u.ac.jp
}

\begin{abstract}
The Daphnia galeata population in Lake Biwa (Japan) had almost ceased producing resting eggs by the 1980s. To examine whether D. galeata had lost the ability to produce resting eggs, or if chemical contamination was inhibiting resting egg production, individuals collected in fall (November) and late winter (March), were reared in the laboratory. More than 50\% of these D. galeata individuals produced resting eggs irrespective of the month of collection, when reared with food supplied at a level lower than that available during the maternal generation. The results reflect that $\mathrm{D}$. galeata in Lake Biwa have a high ability to produce resting eggs when appropriate stimuli are provided. As chemical substances, such as endocrine disrupters, are known to inhibit resting egg production in Daphnia and these accumulate in lake sediments, we tested whether Daphnia individuals produce resting eggs when reared in sediment-conditioned lake water. In sediment-conditioned lake water, only a few Daphnia that were collected in March produced resting eggs, while 50\% of the individuals collected in November produced resting eggs. Thus, D. galeata collected from Lake Biwa are able to produce resting eggs, but genetic variation likely leads to variation in resting egg production in the presence of chemical contaminants. These results suggest that the recent decrease in the resting egg production of Daphnia populations in Lake Biwa is mainly due to a decrease in the strength of the environmental queue that stimulates resting egg production rather than a genetic shift to strains that have a lower ability to produce resting eggs; yet, we cannot rule out the possibility that a chemical contamination plays a role in the decrease of resting egg production.
\end{abstract}

Key words: resting eggs, Lake Biwa, Daphnia galeata, environmental conditions, life history, experimental tests.

Received: June 2012. Accepted: September 2013

\section{INTRODUCTION}

Planktonic cladocerans play key roles in freshwater ecosystems as efficient grazers of phytoplankton and food sources for invertebrate and fish predators (Dodson and Hanazato, 1995; Carpenter and Kitchell, 1996; Lampert, 2006). During periods of harsh environmental conditions, the production of resting eggs through sexual reproduction that become dormant is a key life history characteristic that allows cladoceran populations to persist within given habitats (Mellors, 1975; Hairston, 1996; Cáceres, 1997; Cáceres and Tessier, 2004b). When the environmental conditions again become favourable for sustaining planktonic populations, some resting eggs hatch and, through asexual production of parthenogenetic/subitaneous eggs, these planktonic populations quickly build up in size during following seasons.

For Daphnia, which are typical planktonic cladocerans in lakes, sexual reproduction is induced by various natural environmental stimuli including decreased food levels (Alekseev and Lampert, 2001; LaMontagne and McCauley, 2001), degree of crowding (Cáceres, 1997; Ban et al., 2009), intensity of predation pressure (Mellors, 1975; Ślusarczyk, 2001), and length of photoperiod
(Alekseev and Lampert, 2001). Jankowski and Straile (2003) suggested that eutrophication may cause a decreased sexual reproduction in Daphnia species through, for example, changes in the genetic structure of the populations (Brede et al., 2009). In addition, Shurin and Dodson (1997) and Dodson et al. (1999a, 1999b) showed that anthropogenic perturbations, such as endocrine disrupter contamination, can inhibit sexual reproduction of Daphnia species. These endocrine disrupters are known to accumulate in lake sediments for long periods, even if photolysis readily decreases the concentrations in lake water (Soares et al., 2008). Therefore, residual endocrine disrupter contamination in lake sediments may inhibit resting egg production over extended periods. These findings suggest that resting egg production of Daphnia is sensitive not only to natural environmental stimuli but also to anthropogenic perturbations.

Sexual reproduction and therefore the production of resting eggs may decrease if the environmental conditions are favourable for a Daphnia species all through the year. In general, resting egg production is advantageous to planktonic individuals to overcome harsh periods. However, in the absence of harsh environmental conditions, 
resting egg production may decrease individual fitness because only two eggs that do not hatch immediately are produced (Lynch, 1983). The frequency of resting egg production was found to be lower in Daphnia populations that persist with high numbers all through the year than in those that disappear from the water column during some seasons (Cáceres and Tessier, 2004a, 2004b). Furthermore, recent studies have shown intra-specific variation in sexual reproduction in response to given conditions (Tessier and Cáceres, 2004; Fitzsimmons and Innes, 2006). If harsh seasons were to disappear due to environmental changes that enable Daphnia to persist through the year in the water column, then genetic strains that are sensitive to environmental stimuli for triggering sexual reproduction may be outcompeted by less sensitive lines because of decreased individual fitness, at least with respect to resting egg production.

In Lake Biwa, the largest lake in Japan, Daphnia galeata was the sole Daphnia species after the 1960s, except during 1999 when D. pulicaria suddenly appeared (Urabe et al., 2003). Based on ephippia (resting egg pouches) counts in dated sediment samples during the $20^{\text {th }}$ century, resting egg production of D. galeata has declined since the 1980s (Tsugeki et al., 2009) despite this species dominating the zooplankton community of Lake Biwa over the same period (Okamoto, 1984; Kawabata, 1987; Urabe et al., 1995; Yoshida et al., 2001). In Lake Biwa, D. galeata was rare in winter sampling before 1980 but became more abundant, even in winter, thereafter, suggesting that $D$. galeata could overwinter and successfully persist without producing resting eggs since 1980 (Tsugeki et al., 2009). We suggested earlier that the decrease of resting egg production and the increase of overwintering individuals may have been induced by winter warming (Tsugeki et al., 2009). Warming in winter generally weakens vertical mixing of lake water and shortens the holomixing period. Reflecting the weakened vertical mixing in winter, the dominant phytoplankton species in winter shifted from large diatom, i.e. Aulacoseira nipponica, to flagellated algae such as Cryptomonas spp. and Rhodomonas sp. in the 1980s (Tsugeki et al., 2010). These flagellated algae are edible and highly nutritious to Daphnia (Ahlgren et al., 1990), while A. nipponica is unpalatable as a food source for these animals because of the large colony size (Urabe et al., 1996). Thus, winter warming may have improved food conditions and, consequently, favoured the overwintering of D. galeata as zooplankton (Tsugeki et al., 2009). Because D. galeata can persist through the year without producing resting eggs, we hypothesize that Daphnia individuals currently found in Lake Biwa may have lost the ability to produce resting eggs or have a lowered sensitivity to the environmental stimuli for producing resting eggs.

Here, we tested this hypothesis by examining the fre- quency of resting egg production by $D$. galeata individuals from Lake Biwa under environmental stimuli that typically induce resting egg production. Given that genetic variation among clones affects sexual responses (Innes and Singleton, 2000) and genetically different individuals are dominant in different seasons (Carvalho and Crisp, 1987; Jankowski and Straile, 2004; Paul et al., 2012), we used Daphnia individuals collected in fall and late winter. Daphnia individuals collected in late winter likely overwintered in the water column as planktonic individuals, and we expect that they would invest less for resting egg production compared to individuals collected in fall. We also examined effects of the Lake Biwa sediments on resting egg production of Daphnia, because if the lake was exposed to artificially synthesised chemicals like endocrine disrupters, these were likely accumulated in the lake sediments (Soares et al., 2008).

\section{METHODS}

\section{Daphnia in Lake Biwa}

According to mitochondrial gene sequences, Hyalodaphnia individuals in Lake Biwa belong to the Holarctic B clade of D. galeata (Ishida and Taylor, 2007). In the Japanese islands, $D$. dentifera, another taxon of the $D$. longispina-complex, are also present, mainly in lakes at high latitudes and altitudes, and often hybridise with $D$. galeata (Ishida et al., 2011). We did not examine if the $D$. galeata population in Lake Biwa includes hybrids with $D$. dentifera. However, since most individuals have a well-developed crest on the head, a typical morphological feature of D. galeata (Ishida et al., 2011), we treated Daphnia individuals in this study as D. galeata.

\section{Laboratory experiments}

D. galeata individuals collected at an offshore site in the north basin of Lake Biwa in fall (November 2001) and late winter (March 2002) were cultured at a controlled temperature $\left(20^{\circ} \mathrm{C}\right)$ with a non-limiting amount of algal food until May to June 2002, when laboratory experiments were performed. D. galeata individuals collected in November and March were cultured without separation of clones within each collection and were designated as November and March strains, respectively.

Water was collected every other day from an offshore site in the north basin of Lake Biwa for use in the experiments. Sediment was collected once at $45 \mathrm{~m}$ deep in the north basin of Lake Biwa using an Ekman-Birge grab sampler $\left(225 \mathrm{~cm}^{2}\right)$ in early May 2002 and was stored in a refrigerator for use during the experiment. Treatment water (lake water and sediment-conditioned lake water) was prepared daily as follows. For sediment-conditioned lake water treatment, $0.5 \mathrm{~g}$ wet weight of lake sediment was suspended in $500 \mathrm{~mL}$ of lake water, well shaken by hand, 
and centrifuged. The supernatant was passed through a GF/F filter (Sigma-Aldrich, St. Louis, MO, USA). The GF/F (Sigma-Aldrich) filtrate of lake water was prepared for use as the lake water treatment. Green algae, Scenedesmus acutus, as food source for Daphnia were obtained from stock cultures in a flow through chamber with COMBO medium (Kilham et al., 1998) for over two years under constant lab conditions. The algal cell density (as food concentration) was determined microscopically and converted into carbon weight using a conversion factor determined previously (Urabe et al., 2003).

The life history experiments using November and March strains were conducted simultaneously for both treatment water types. The experiments were designed to stimulate resting egg production, such as reducing the food supply to a level lower than that available during the maternal generation (Alekseev and Lampert, 2001; LaMontagne and McCauley, 2001). To initiate the experiment, 10 neonates $\left(1^{\text {st }}\right.$ generation$)$ from maternal individuals grown with a non-limiting supply of nutrient-sufficient green algae (Scenedesmus actus), a suitable food for Daphnia, were placed in $300 \mathrm{~mL}$ of each treatment water with algae at 1.0 $\mathrm{mg} \mathrm{C} \mathrm{L}{ }^{-1}$ (one individual $/ 30 \mathrm{~mL}$ ). These individuals were raised until they produced second or third clutches. The treatment water was changed daily along with renewal of the algal food supply. Neonates ( $2^{\text {nd }}$ generation) were collected within $24 \mathrm{~h}$ of release from the second and third clutches of the $1^{\text {st }}$ generation, and 15 neonates of the $2^{\text {nd }}$ generation were placed in each flask containing $150 \mathrm{~mL}$ of each treatment water (one individual $/ 10 \mathrm{~mL}$ ) and reared with algae at $0.4 \mathrm{mg} \mathrm{C} \mathrm{L}^{-1}$. Each treatment was made in duplicate, and treatment water was changed daily with renewal of food. At 8 to 13 days after the start of the experiment, we introduced two male $D$. galeata into each flask to stimulate sexual reproduction. When a female with ephippia was found, the individual was counted and removed from the flask along with $10 \mathrm{~mL}$ of the treatment water in order to avoid double counting of individuals. Using this data, the frequency of maternal individuals producing resting eggs was determined. The water volume was always adjusted to maintain a constant density (1 individual $/ 10 \mathrm{~mL}$ ). Daily observations were continued until the $2^{\text {nd }}$ generation individuals reached 30 days.

\section{Statistical analysis}

The effects of the Daphnia strains collected in November and March and treatment water on the frequency of resting egg production were examined by two-way ANOVA with a fixed effects model using SPSS 11.0 software (SPSS Inc., Chicago, IL, USA). Prior to statistical analysis, the frequency data were arcsine-transformed to stabilise the variance. An assumption of homoscedasticity was confirmed by Cochran's $C$-test at the $5 \%$ significance level $(\mathrm{C}=0.451 ; \mathrm{P}>0.05)$.

\section{RESULTS}

When sexual reproduction was artificially induced, $D$. galeata produced resting eggs in all treatment combinations (Fig. 1). However, the frequency of resting egg production differed according to the collection month and treatment water. For the November strain, more than $60 \%$ of the individuals produced resting eggs irrespective of the treatment water. For the March strain, $50 \%$ of the individuals produced resting eggs in lake water. However, for this strain, less than $10 \%$ of the individuals produced resting eggs in sediment-conditioned lake water. According to ANOVA, the effect of the strain on the frequency of resting egg production was significant $\left(F_{1,4}=19.23\right.$; $\mathrm{P}<0.05)$, but differed for experimental water $\left(F_{1,4}=8.45\right.$; $\mathrm{P}<0.05)$. No consistent effect was found for the main effect of treatment water type $\left(F_{1,4}=4.63 ; \mathrm{P}>0.05\right)$.

\section{DISCUSSION}

Daphnia populations are known to produce resting eggs during late spring and/or fall (Cáceres, 1998; Alekseev and Lampert, 2001). Thus, individuals collected in November and March are at stages after or before the resting-egg-producing seasons. Because the genetic structure of Daphnia populations can change seasonally (Carvalho and Crisp, 1987; Jankowski and Straile, 2004) and be-

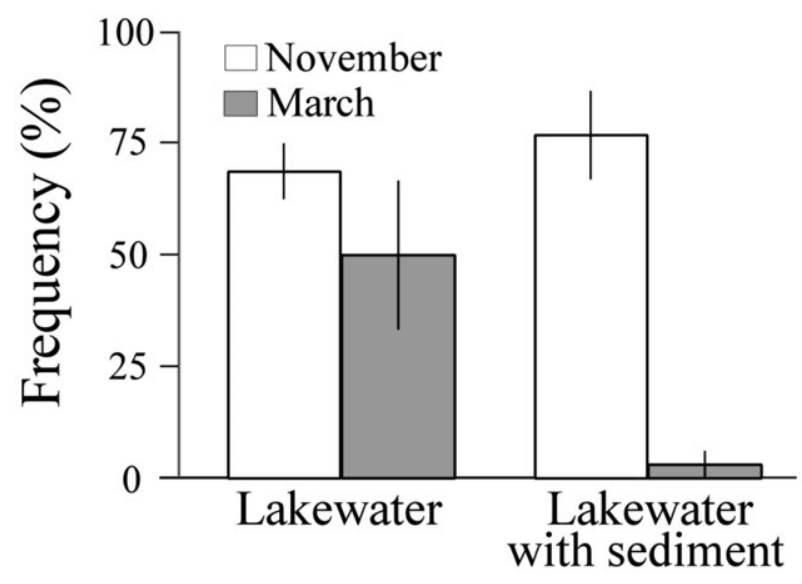

\section{Experimental water}

Fig. 1. Effect of sampling month and treatment water on resting egg production frequency of $D$. galeata for artificially induced sexual reproduction. The difference in frequency was significant between March and November strains and depended on treatment water (2-way ANOVA, main effect for strains: $F_{1,4}=19.23$, $\mathrm{P}<0.05$; interaction effect for strains and treatment water: $\left.F_{1,4}=8.45, \mathrm{P}<0.05\right)$. No consistent effect was observed for the main effect of the kind of experimental treatment $\left(F_{1,4}=4.63\right.$, $\mathrm{P}>0.05)$. Error bars indicate the standard deviation $(n=2)$. 
cause resting egg production varies among clones of Daphnia species (Innes and Singleton, 2000), we expected the rate of resting egg production to differ among individuals collected in different seasons. In particular, as Daphnia collected in March were likely to be overwintering individuals that did not go through a dormant stage, such as resting eggs, we expected them to have a much lower frequency of resting egg production. The March strain did produce resting eggs at a lower frequency compared to the November strain, supporting this hypothesis. However, both strains produced resting eggs at a frequency of $>50 \%$ in lake water. These frequencies are comparable to the resting egg production rates reported for other experimental studies on Daphnia species (Alekseev and Lampert, 2001; LaMontagne and McCauley, 2001). Thus, we conclude that even D. galeata individuals collected in March maintained the ability to produce resting eggs comparable to those of Daphnia in other studies.

However, for the sediment-conditioned lake water treatment, the March strain, unlike the November strain, individuals had a remarkably reduced resting egg production frequency. These results suggest that Lake Biwa sediments contain chemical substances that inhibit resting egg production in D. galeata and that sensitivity to these substances differs between these strains. Endocrine disrupters, such as nonylphenols, are known to inhibit sexual reproduction and, thus, resting egg production of Daphnia (Shurin and Dodson, 1997; Dodson et al., 1999a, 1999b). In Lake Biwa, endocrine disrupters like nonylphenols and ethinylestradiol were detected in lake water during the period from 2000-2001 (Yoshida et al., 2009) and in inflowing rivers in 1998-1999 (Tsuda et al., 2000). These endocrine disrupters generally accumulate in lake sediments for long (Soares et al., 2008). Thus, the low frequency of resting egg production by the March strain in the sediment-conditioned water may have been due to the presence of endocrine disrupters in lake sediments. In future studies, detailed analyses of chemical substances in the sediment will be necessary to clarify the specific inhibitors of resting egg production. Still, the concentration of chemicals resuspended from the sediment in the conditioned water was probably much higher than that in natural lake water, given the high ratio of sediment to lake water used in our experiment. Thus, our method may have overestimated the inhibitory effects of chemical contaminants in the lake sediments.

Nutrients extracted from the sediment in the conditioning step could enrich the phytoplankton during the incubation. Yet, while the November strain showed a high frequency of resting egg production in sediment-conditioned lake water, the March strain showed reduced frequency of resting egg production in sediment-conditioned lake water. It is difficult to attribute the differences in resting egg production between collection month to the en- richment effects of sediment extracts as we used green algae that were cultured under nutritionally sufficient conditions and the algal food was changed with the treatment water every day. Therefore, there should not be any large differences in food condition between treatments with and without sediment conditioning.

In Lake Biwa, D. galeata populations produced abundant quantities of resting eggs before the 1980s, but production decreased thereafter despite the high population density (Tsugeki et al., 2009). The decrease in resting egg production in Lake Biwa cannot be explained fully by contamination via chemical substances, such as endocrine disrupters, inhibiting resting egg production, because both the November and March strains produced resting eggs at high frequencies in our experiments with lake water and because the resting egg production of the November strain was unaffected by the sediment conditioning treatment. Caceres and Tessier (2004a, 2004b) showed that the frequency of resting egg production was lower in Daphnia populations that persisted in high numbers all through the year than in populations that disappeared from the water column during some seasons. In Lake Constance, Jankowski and Straile (2003) reported that the Daphnia hyalina population had demonstrated a decreased frequency of resting egg production during the course of eutrophication. They argued that the decease may be related to an increased possibility to overwinter in plankton after eutrophication because resting egg production is no longer necessary for overwintering when the environmental conditions are favourable during all through the year. In Lake Biwa, the number of $D$. galeata individuals overwintering in plankton has increased in recent years, suggesting that resting egg production may not be critical for sustaining the population (Tsugeki et al., 2009).

\section{CONCLUSIONS}

In sum, we hypothesized that the recent decrease in resting egg production by the $D$. galeata population in Lake Biwa is due to the dominance of strains or genotypes that have little ability to produce resting eggs. Nonetheless, our results did not support this hypothesis because both the November and March strains produced resting eggs when food level was decreased in daughter generation compared with maternal generation. The result showed that $D$. galeata in Lake Biwa can produce resting eggs when appropriate environmental stimuli were provided. It should be noted that environmental stimuli for inducing resting egg production, such as rigid systematic changes in food supply between generations under the laboratory condition, are not likely to occur in the field. Thus, although the currently used strains produced ephippial eggs under laboratory conditions, the results do not necessarily mean that they will produce these eggs at equal rates under field conditions. Koch et al. (2009) 
showed that the frequency of resting egg production was much lower for Daphnia individuals reared on Cryptomonas compared with those reared on green algae, which suggests that food quality also affects the resting egg production rates of Daphnia species. Interestingly, seasonal phenology and the dominant species of the algal community in Lake Biwa has recently changed due to changes in seasonal meteorological conditions, related in part to global warming (Tsugeki et al., 2010). This circumstantial evidence suggests that the recent decrease in resting egg production in Daphnia population in Lake Biwa may have been mainly due to a decrease in the strength of the environmental queue that stimulates resting egg production rather than a genetic shift toward strains having a lower ability to produce resting eggs, although we cannot rule out the possibility that chemical contamination plays a role in the decrease of the resting egg production.

\section{ACKNOWLEDGMENTS}

We thank Mr. Jun Togari and Mr. Takahiro Miyano for their assistance in experiments and sampling lake water from Lake Biwa. This study was supported by a Grant-inAid for Scientific Research B (No. 12440218) and by the Environment Research and Technology Development Fund (D-1002) of the Ministry of the Environment, Japan to JU, and partly supported by a Japan Society for the Promotion of Science (JSPS) postdoctoral fellowship to NKT.

\section{REFERENCES}

Ahlgren G, Lundstedt L, Brett M, Forsberg C, 1990. Lipid composition and food quality of some freshwater phytoplankton for cladoceran zooplankters. J. Plankton Res. 12:809-818.

Alekseev V, Lampert W, 2001. Maternal control of resting-egg production in Daphnia. Nature 414:899-901.

Ban S, Tenma H, Mori T, Nishimura K, 2009. Effects of physical interference on life history shifts in Daphnia pulex. J. Exp. Biol. 212:3174-3183.

Brede N, Sandrock C, Straile D, Spaak P, Jankowski T, Streit B, Schwenk K, 2009. The impact of human-made ecological changes on the genetic architecture of Daphnia species. P. Natl. Acad. Sci. USA 106:4758-4763.

Cáceres CE, 1997. Temporal variation, dormancy, and coexistence: a field test of the storage effect. P. Natl. Acad. Sci. USA 94:9171-9175

Cáceres CE, 1998. Interspecific variation in the abundance, production, and emergence of Daphnia diapausing eggs. Ecology 79:1699-1710.

Cáceres CE, Tessier AJ, 2004a. Incidence of diapause varies among populations of Daphnia pulicaria. Oecologia 141:425-431.

Cáceres CE, Tessier AJ, 2004b. To sink or swim: variable diapause strategies among Daphnia species. Limnol. Oceanogr. 49:1333-1340.

Carpenter SR, Kitchell JF, 1996. The trophic cascade in lakes. Cambridge University Press, Cambridge: 385 pp.
Carvalho GR, Crisp DJ, 1987. The clonal ecology of Daphnia magna (Crustacea:Cladocera). I. Temporal changes in the clonal structure of a natural population. J. Anim. Ecol. 56: 453-468.

Dodson SI, Hanazato T, 1995. Commentary on effects of anthropogenic and natural organic chemicals on development, swimming behavior, and reproduction of Daphnia, a key member of aquatic ecosystems. Environ. Health Persp. 103:7-11.

Dodson SI, Merritt CM, Torrentera L, Winter KM, Tornehl CK, Girvin K, 1999a. Dieldrin reduces male production and sex ratio in Daphnia galeata mendotae. Toxicol. Ind. Health 15:192-199.

Dodson SI, Merritt CM, Shannahan J-P, Shults CM, 1999b. Low exposure concentrations of atrazine increase male production in Daphnia pulicaria. Environ. Toxicol. Chem. 18:1568-1573.

Fitzsimmons JM, Innes DJ, 2006. Inter-genotype variation in reproductive response to crowding among Daphnia pulex. Hydrobiologia 568:187-205.

Hairston NG Jr., 1996. Zooplankton egg banks as biotic reservoirs in changing environments. Limnol. Oceanogr. 41:1087-1092.

Innes D, Singleton D, 2000. Variation in allocation to sexual and asexual reproduction among clones of cyclically parthenogenetic Daphnia pulex (Crustacea: Cladocera). Biol. J. Linn. Soc. 71:771-787.

Ishida S, Takahashi A, Matsushima N, Yokoyama J, Makino W, Urabe J, Kawata M, 2011. The long-term consequences of hybridization between the two Daphnia species, D. galeata and D. dentifera, in mature habitats. BMC Evol. Biol. 11:209.

Ishida S, Taylor DJ, 2007. Quaternary diversification in a sexual Holarctic zooplankter, Daphnia galeata. Mol. Ecol. 16:569582.

Jankowski T, Straile D, 2003. A comparison of egg-bank and long-term plankton dynamics of two Daphnia species, $D$. hyalina and D. galeata: potentials and limits of reconstruction. Limnol. Oceanogr. 48:1948-1955.

Jankowski T, Straile D, 2004. Allochronic differentiation among Daphnia species, hybrids and backcrosses: the importance of sexual reproduction for population dynamics and genetic architecture. J. Evolution Biol. 17:312-321.

Kawabata K, 1987. Ecology of large phytoplankton in Lake Biwa: population dynamics and food relations with zooplankters. Bull. Plankton Soc. Jpn. 34:165-172.

Kilham SS, Kreeger DA, Lynn SG, Goulden CE, Herrera L, 1998. COMBO: a defined freshwater culture medium for algae and zooplankton. Hydrobiologia 377:147-159.

Koch U, von Elert E, Straile D, 2009. Food quality triggers the reproductive mode in the cyclical parthenogen Daphnia (Cladocera). Oecologia 159:317-324.

LaMontagne JM, McCauley E, 2001. Maternal effects in Daphnia: what mothers are telling their offspring and do they listen? Ecol. Lett. 4:64-71.

Lampert W, 2006. Daphnia: model herbivore, predator and prey. Pol. J. Ecol. 54:607-620.

Lynch M, 1983. Ecological genetics of Daphnia pulex. Evolution 37:358-374.

Mellors WK, 1975. Selective predation of ephippial Daphnia 
and the resistance of ephippial eggs to digestion. Ecology 56:974-980.

Okamoto K, 1984. Size-selective feeding of Daphnia logispina hyalina and Eodiaptomus japonicus on a natural phytoplankton assemblage with the fractionizing method. Mem. Fac. Sci. Kyoto Univ. Ser. Biol. 9:23-40.

Paul RJ, Mertenskötter A, Pinkhaus O, Pirow R, Gigengack U, Buchen I, Koch M, Horn W, Zeis B, 2012. Seasonal and interannual changes in water temperature affect the genetic structure of a Daphnia assemblage (D. longispina complex) through genotype-specific thermal tolerances. Limnol. Oceanogr. 57:619-633.

Shurin JB, Dodson SI, 1997. Sublethal toxic effects of cyanobacteria and nonylphenol on environmental sex determination and development in Daphnia. Environ. Toxicol. Chem. 16:1269-1276.

Ślusarczyk ML, 2001. Food threshold for diapause in Daphnia under the threat of fish predation. Ecology 82:1089-1096.

Soares A, Guieysse B, Jefferson B, Cartmell E, Lester J, 2008. Nonylphenol in the environment: a critical review on occurrence, fate, toxicity and treatment in wastewaters. Environ. Int. 34:1033-1049.

Tessier AJ, Cáceres CE, 2004. Differentiation in sex investment by clones and populations of Daphnia. Ecol. Lett. 7:695703.

Tsuda T, Takino A, Kojima M, Harada H, Muraki K, Tsuji M,
2000. 4-Nonylphenols and 4-tert-octylphenol in water and fish from rivers flowing into Lake Biwa. Chemosphere 41:757-762.

Tsugeki NK, Ishida S, Urabe J, 2009. Sedimentary records of reduction in resting egg production of Daphnia galeata in Lake Biwa during the $20^{\text {th }}$ century: a possible effect of winter warming. J. Paleolimnol. 42:155-165.

Tsugeki NK, Urabe J, Hayami Y, Kuwae M, Nakanishi M, 2010. Phytoplankton dynamics in Lake Biwa during the $20^{\text {th }}$ century: complex responses to climate variation and changes in nutrient status. J. Paleolimnol. 44:69-83.

Urabe J, Kawabata K, Nakanishi M, Shimizu K, 1996. Grazing and food size selection of zooplankton community in Lake Biwa during BITEX'93. Jpn. J. Limnol. 57:27-37.

Urabe J, Nakanishi M, Kawabata K, 1995. Contribution of metazoan plankton to the cycling of nitrogen and phosphorus in Lake Biwa. Limnol. Oceanogr. 40:232-241.

Urabe J, Togari J, Elser JJ, 2003. Stoichiometric impacts of increased carbon dioxide on a planktonic herbivore. Glob. Change. Biol. 9:818-825.

Yoshida T, Kagami M, Gurung TB, Urabe J, 2001. Seasonal succession of zooplankton in the north basin of Lake Biwa. Aquat. Ecol. 35:19-29.

Yoshida H, Kudari S, Hori T, Sugiyama M, 2009. Distribution of particulate nonylphenol in Lake Biwa, Japan. Water Air Soil Poll. 200:267-276. 